\title{
ACESSO, UTILIZAÇÃO E ACEITAÇÃO DOS SERVIÇOS DE DERMATOLOGIA DE UM CENTRO DE SAÚDE ESCOLA SOB O MODO DE VER DOS HANSENIANOS*
}

Nilce Piva Adami**

Trata-se de um Centro de Estudo de caso visando a análise do acesso, utilização e aceitação dos serviços de dermatologia de um Centro de Saúde Escola (CSE), envolvendo principalmente a história oral narrada por 27 hansenianos. O acesso ao CSE - na sua vertente organizativa - ocorreu sem obstáculos, excetuando-se, porém, o atendimento em serviços de retaguarda. A utilização dos serviços foi maior que o padrão estabelecido face ao atendimento prestado a episódios próprios ou não da hanseníase. A aceitação dos serviços recebidos foi consensual, destacando-se os atributos técnicos e de relacionamento interpessoal.

UNITERMOS: Administração de serviços de saúde. Avaliação de serviços de saúde. Hanseníase.

\section{I - Introdução}

O pressuposto que conduziu nesta pesquisa foi o de procurar desvendar porquê a grande maioria dos hansenianos em controle num Centro de Saúde Escola (CSE), residia em local distante desta Unidade Básica de Saúde (UBS). A questão do estigma social presente na hanseníase, endemia nacional da maior importância, seria a razão principal para a busca de tratamento em local afastado de suas moradias?

E considerando ainda, o hanseniano como sujeito do processo avaliativo dos serviços de

\footnotetext{
${ }^{*}$ Resumo da Tese de Livre-Docência apresentada à Escola Paulista de Medicina, 1991. Pesquisa financiada pela FAPESP.

**Professora Adjunta do Departamento de Enfermagem da Escola Paulista de Medicina. Rua Napoleão de Barros, 754. São Paulo, SP - Brasil.
} 
saúde, buscou-se desvelar a sua percepção sobre a existência de barreiras organizativas que dificultariam o acesso inicial e a utilização dos serviços do CSE e sua aceitação, conformando assim, a estrutura básica do objeto deste estudo.

Uma vez definido o objeto, construiu-se quadro teórico que fundamentou a pesquisa apresentando a seguir.

A $8^{a}$ Conferência Nacional de Saúde realizada em 1986 consagrou o conceito ampliado de saúde decorrente de suas amplas relações intersetoriais implicando, portanto, em qualidade de vida e não somente o acesso a serviços de saúde como direito do cidadão e dever do Estado (CONFERÊNCIA NACIONAL DE SAÚDE ${ }^{6}$ ).

Quanto a este dever, foram definidos alguns princípios básicos que devem ser considerados no processo de reformulação do setor saúde como um todo, e que são categorizados em finalísticos e em organizativos ou estratégicos (COMISSÃO NACIONAL DE REFORMAS SANITÁRIAS ${ }^{5}$ ).

Dentre estes conjuntos citam-se a seguir, aqueles de interesse para este estudo:

- a "universalização, que consiste em estender o acesso a toda a população, através do setor público, independente dos vínculos de contribuição e das condições sócio-econômicas de cada indivíduo";

- a eqüidade, consiste em fazer com que esse acesso não seja feito da constituição de clientelas, mas sim que todos tenham direito aos mesmos serviços em todo o país independentemente da vinculação funcional, da posição social na hierarquia ocupacional em local de moradia ou trabalho...;

- a participação consiste, antes de tudo, no reconhecimento do direito dos usuários (a população) de exercerem o controle sobre a formulação e a execução da política de saúde, assegurando ao mesmo tempo, a participação efetiva dos profissionais de saúde nesse processo;

- por regionalização/hierarquização entende-se a forma e assegurar o acesso aos recursos tecnológicos necessários ao atendimento de todo e qualquer cidadão, na complexidade que cada caso mereça..."

Quanto ao acesso de natureza funcional, sua evidência maior concretiza-se pelo uso do serviço de saúde e não simplesmente pela sua existência, abrangendo o início e a continuidade do cuidado (CASTELLANOS ROBAYO ${ }^{4}$ ). É representado pelo consumo real e pode ser mensurado pelo nível do uso do serviço em relação à necessidade. A resistência, por sua vez, se materializa no conjunto de obstáculos que se interpõem na busca e obtenção dos cuidados, os quais se originam nos recursos de saúde (FRENK $\left.{ }^{11}\right)$.

Para CORDERA PASTOR ${ }^{7}$ a aceitação consiste na satisfação da população em relação aos serviços. Estes podem ser disponíveis, acessíveis e custeáveis; no entanto, podem não ser aceitável pela população, necessariamente.

Para CASANUEVA e et $\mathrm{al}^{3}$ a aceitação inclui vários aspectos, dentre os quais salientase a expectativa das pessoas referente à qualidade da assistência, ressaltada, também, por 
DONABEDIAN $^{8}$. FIELDER ${ }^{10}$, refere que para o paciente aceitar o serviço, ele deve ter confiança na competência técnica e no tratamento humano dispensado pelo profissional que o assiste.

Quanto a satisfação do paciente, REIS et $\mathrm{al}^{16}$ tendo por base LEBOW, comentam dentre vários fatores que afetam a percepção do usuário, "as experiências anteriores de cuidado médico recebido, em que condições elas se deram e o seu estado atual de saúde". Estes autores, a partir de resultados preliminares de vários estudos realizados sobre a satisfação do paciente como medida da qualidade dos cuidados de saúde, inferem que os fatores mais importantes que influem na percepção dos pacientes são: "interesse pessoal do médico pelo paciente, acessibilidade, bons médicos, acompanhamento por pessoal bem treinado, informações dos médicos, pessoal solicito e privacidade."

DONABEDIAN citado também por REIS et $\mathrm{al}^{16}$ sugere que o estudo da satisfação constitui um indicador aproximado da qualidade do cuidado à saúde.

PEREZ; IBARRA ${ }^{15}$ concluem que os aspectos que mais influem na satisfação do paciente são: informações sobre a sua doença e o tratamento indicado, e a relação que o médico estabelece com ele e o critério que o cliente tem sobre a competência do profissional que $\mathrm{o}$ assiste.

A questão da eqüidade é colocada como um dos desafios para o sistema de saúde. Fundamenta-se em dois princípios: o da eqüidade horizontal e vertical: o primeiro busca garantir que indivíduos que tenham condições de saúde semelhantes sejam tratados igualmente; o segundo considera que indivíduos que tenham problemas desiguais, sejam tratados em função das peculiaridades de cada caso $\left(M O O N E Y^{13}\right)$.

A participação da população como conceito genérico e abrangente tem sido definida e redefinida ganhando, em cada momento histórico, significados bastantes diversos, dentre os quais cita-se o acesso (YUNES ${ }^{19}$ ).

Implica na idéia de participação de usuário e profissionais tanto nos serviços públicos como nos privados que mantêm convênios e contratos com as fontes públicas de financiamentos. As formas de expressões podem ocorrer via organizações formais destes segmentos como nos próprios serviços quando se promove efetivamente a participação da clientela e dos trabalhadores de saúde nas várias etapas do processo assistencial (ABRASCO ${ }^{1}$ E RODRIGUEZ NETO ${ }^{17}$ ).

A regionalização como modelo de organização de todos os serviços de saúde hierarquizados em uma rede de complexidade crescente, numa determinada área geográfica, deve ser entendida como uma das estratégias preconizadas para facilitar o acesso aos serviços de saúde. A hierarquização pressupõe um sistema de referência e contrareferência visando a possibilidade de se assistir pessoas com nível de resolutividade a partir dos serviços de menor complexidade $\left(\right.$ BRAVO $\left.^{2}\right)$. 


\section{II - Objetivos}

A intenção deste estudo, a partir do modo de ver uma população de hansenianos, foi a de conhecer o grau de acessibilidade organizava dos serviços de Dermatologia de um Centro de Saúde Escola; buscou-se também, analisar as implicações deste acesso na utilização e aceitação desses serviços para qualificar o atendimento prestado a esses pacientes.

\section{III - Método}

Esta pesquisa é de natureza qualitativa, do tipo Estudo de Caso, envolvendo precipuamente a coleta da história oral narrada por pacientes de hanseníase, considerados como sujeitos principais da pesquisa.

Inicialmente não foi estabelecido o número de pacientes a serem incluídos no estudo ficando esta determinação em função do momento em que se observasse uma certa reincidência das informações obtidas sobre o fenômeno em estudo, sem desprezar, porém, as informações ímpares com potencial explicativo (MINAYO ${ }^{12}$ ).

Por essa razão, a amostra incluiu 27 pacientes, que apresentavam idade igual ou até maior que 15 anos, inscritos no Programa de Controle da Hanseníase ( $\mathrm{PCH}$ ) até maio de 1989, para abranger hansenianos que pudessem narrar como percebiam o atendimento prestado no CSE em função de o terem freqüentado há pelo menos um ano.

As entrevistas com esses pacientes foram realizadas em ambiente privativo, numa sala situada no mesmo piso onde se localizava área de Dermatologia. Quando o paciente preenchia os critérios de inclusão supracitados, o mesmo era encaminhado a esta sala, pelo profissional que o atendia. Após uma conversa informal onde se procurava estabelecer um clima de simpatia e de confiança entre as entrevistadoras e o entrevistado o paciente era esclarecido sobre: a identidade da pesquisadora, os objetivos da pesquisa e a duração média da entrevista; eram assegurados também, o sigilo e o anonimato em relação ao informante. Após estas informações, era solicitado seu consentimento para realizar a mesma e gravar seu depoimento. A entrevista foi semi-estruturada, tendo por guia um roteiro que incluiu questões básicas envolvidas no objetivo do estudo, procurando-se aplicar no decorrer do seu processo, os principais citados por TRIVINOS. As transcrições ocorreram após o término de cada entrevista, visando uma análise que possibilitasse o aperfeiçoamento desse processo não ocorrendo nenhuma recusa do paciente quer para ser entrevistado quer para a gravação do seu depoimento.

Além dessa metodologia, a autora observou o atendimento prestado ao hanseniano, 
entrevistou os profissionais que atuam no $\mathrm{PCH}$, realizou análise documental e de dados registrados nos prontuários dos pacientes entrevistados. Este procedimento buscou aplicar a técnica de triangulação na coleta de dados com vista à "abranger a máxima amplitude da descrição, explicação e compreensão" do fenômeno estudado (TRIVINOS ${ }^{18}$ ).

A coleta de informações no CSE estendeu-se de junho a agosto de 1990.

\section{IV - Resultados}

\section{O Programa de Controle da Hanseníase}

No decorrer da observação realizada, procurou-se apreender o processo de atendimento ao hanseniano, descrito a seguir.

O PCH teve início em 1980 e suas atividades são realizadas por uma equipe multiprofissional no período da manhã e os hansenianos que procuram o CSE são matriculados independentemente de residirem na área de abrangência do CSE.

Por ocasião do atendimento, os hansenianos permanecem na sala de espera comum à clientela que demanda para matrícula, marcação de consultas e outros serviços oferecidos no andar térreo, ocorrendo assim, uma integração física da assistência prestada a esses pacientes. As consultas podem ser marcadas pessoalmente ou por telefone e os pacientes sem agendamento que apresentam alguma queixa, são atendidos no mesmo dia.

O PCH segue as diretrizes técnicas da Divisão Nacional de Dermatologia Sanitária (DNDS)*** do Ministério da Saúde (MS) e do Grupo Especial de Desenvolvimento de Programas GEPRO/hanseníase da SES de São Paulo e desenvolve as seguintes atividades: consultas médicas e de enfermagem, curativos e imobilizações, prevenção de incapacidades físicas por meio de técnicas simples, baciloscopia, teste de Mitsuda, grupos educativos - um se segmento para discussão do estigma e orientação sobre a doença sobre a doença e o outro de prevenção de incapacidades físicas, controle de comunicantes e vigilância epidemiológica. Os pacientes são agendados uma vez por ano para o serviço de ortóptica e as mulheres para consulta ginecológica, com a mesma periodicidade. O exame histopatológico e os exames subsidiários são realizados em laboratório do Hospital São Paulo (HSP), o mesmo ocorrendo no caso de encaminhamentos para as diversas especialidades deste serviço.

Os pacientes que necessitam de internação, são encaminhados para a enfermaria de Dermatologia do HSP e para o Hospital Padre Bento da Secretaria de Estado da Saúde de São Paulo (SES).

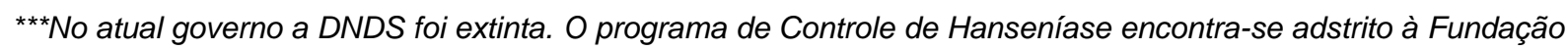
Nacional de Saúde do MS.
} 
Durante a coleta de dados, os grupos educativos encontravam-se desativados há cerca de um mês por falta de demanda de pacientes a estas atividades.

\section{2 . Local de residência, referência de pacientes ao CSE e tempo de controle}

Dos 27 pacientes que participaram do estudo, apenas dois moravam na área de atuação do CSE. Dos 25 restantes, 18 residiam na cidade de São Paulo e sete em outros

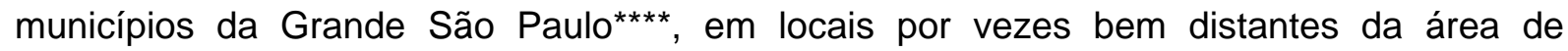
abrangência do CSE, o que implica em dispêndio considerável de tempo para a locomoção e gasto com mais de um transporte. Entretanto, atualmente, deve ser considerado que a integração existente entre os transportes de massa (trem, metrô e ônibus) tem facilitado o acesso ao serviço de saúde, uma vez que este dista cinco quarteirões da Estação Santa Cruz, da linha Norte-Sul do Metrô e que em média são vencidos em 10 minutos de caminhada.

Da amostra estudada, a maioria (16-66,6\%) foi encaminhada pelo HSP, a partir a clientela que procura seus serviços para tratamento, principalmente ambulatorial ou de internação. Na condição de usuários do próprio CSE, encontraram-se 3, sendo que destes 2 eram comunicantes. Os demais foram encaminhados por hospitais da rede privada (2); UBS de SES (3) e apenas, um cliente procurou o CSE, por iniciativa própria, mas, já na condição de doente que fez controle em outro Estado. Estes dados evidenciaram, que o serviço responsável pelo maior número de encaminhamentos ao CSE, é o HSP, em função do intercâmbio existente entre as áreas de dermatologia das duas unidades.

Cerca de $41 \%$ dos pacientes (11) possuíam de 1 a 2 anos incompletos de controle. De 2 a 3 e de 3 a 4 anos incompletos encontraram-se 4 pacientes, respectivamente. De 4 a 5,5 a 6 e 6 a 7 anos incompletos foram observados, 5, 2 e 1 hanseniano, respectivamente.

\section{3 - Acesso organizativo: início e continuidade do controle}

Segundo FERREIRA ${ }^{9}$ é freqüente o "paciente preferir tratar-se em unidade sanitária de outro município que não o da sua residência, seja porque seu local de trabalho está neste outro município (situação comum nas áreas metropolitanas), seja porque prefere tratar-se em local onde existe um especialista, seja porque, em virtude do estigma que a doença acarreta, não deseja apresentar-se como doente na unidade sanitária de seu local de residência."

A questão do emprego se localizar na área do CSE e principalmente a questão do estigma - pressuposto inicial a pesquisa - não foram desveladas nos relatos como motivo de busca de tratamento no CSE.

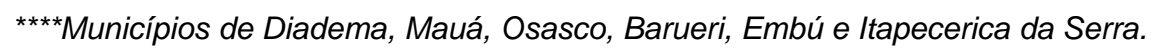


Os hansenianos ao chegarem a esta UBS, gostaram do atendimento e permaneceram em controle neste serviço de saúde, pois, foi consenso entre os pacientes que o acesso inicial ocorreu sem dificuldades. Alguns exemplos ilustram esta questão:

"Foi facinho". "Não demorou muito." "Eles mandou, eu já vim e comecei logo. Foi rapidinho." "Não foi difícil. Logo fui atendida." "No primeiro dia que eu vim, os médicos já atendeu, marcou retorno.Por isso que eu fiquei mesmo aqui, que achei legal." "No dia que saiu o resultado que era essa doença...no mesmo dia ela me encaminhou aqui pro Posto."

Quanto à continuidade do controle, praticamente a situação foi a mesma, quase sem barreiras consideradas dissuasivas por FRENK. Porém emergiram alguns comentários sobre o tempo de espera para ser atendido no dia, ou a demora para fazer exames no HSP. Um ponto muito valorizado pelos pacientes foi o de serem atendidos sem agendamento, quando apresentam algum surto reacional ou outro problema de saúde desvelando-se nas falas a postura de apoio a este tipo de demanda por parte de profissionais do $\mathrm{PCH}$. Alguns exemplos dos depoimentos que abordaram essas questões são relacionadas a seguir:

"Não, aqui prá mim sempre demora muito. Hoje mesmo eu vim, não estava nem com consulta marcada, eu cheguei, já atendi lá e já sai. Eu não posso falar nada daqui."

"Não demora... onde a gente perde muito tempo é n H.S.P. Lá é fora de série."

"Em vista de outros lugares eu acho que é até rápido... porque às vezes eu ficava uma hora e meia, duas horas (outros serviços) aqui acho que é até pouco...

"Não, é tudo muito tranqüilo mesmo. Não acho difícil não. Hoje não tava marcado, né? Eu senti febre essa noite, trinta e nove graus e a Dra. disse que quando eu sentisse qualquer coisa que eu viesse aqui né? Essa consulta tava marcada pro outro dia, mas eu vim logo hoje."

"Até sempre que a enfermeira termina os curativos ela fala assim: Olha qualquer coisa que tiver pode vir! "Então, nada aqui é assim difícil. Quando é para marcar consulta depois de dois mês, eu telefono e marco".

"Eu acho que espero muito aí na sala de espera, só. Demora muito tempo prá ser atendido. Eu sei que as consultas são demoradas, né? de todos os pacientes de dermatologia, porque quando eu estava lá também eu fico um tempão. Gostar eu não gosto, porque ninguém gosta de esperar, eu fico me sentindo incomodada de estar esperando...." 
"É perde um pouco de tempo, né!? Um pouquinho. Então isso me deixa nervosa, quando eu vou passar pelo médico eu já estou assim super nervosa."

"Não, prá mim nunca teve problemas nenhum. O único problema que tá havendo é daqui prá lá né? (se referindo ao HSP). Por exemplo, só prá senhora ver, tem exame que foi pedido o ano passado e hoje que eu consegui marcar um deles!."

Essas falas mostram claramente que os pacientes percebem que são atendidos sem qualquer barreira, principalmente quando comparam o CSE com outros serviços de saúde. Os principais aspectos ressaltados foram: relativa rapidez no atendimento e facilidade para obter uma consulta, principalmente quando apresentam um problema de saúde. Percebe-se em uma fala, que o paciente reconhece que a consulta dermatológica é demorada e em outras que o doente fica "nervoso" e "incomodado" com a espera. Apesar de serem agendados dois pacientes a cada hora de atendimento, a espera se torna maior, quando a consulta médica ou de enfermagem é realizada por estudantes em função do processo ensino/aprendizagem. Os pacientes em outras falas reconheceram essa função do CSE.

Pelos depoimentos citados depreende-se que o início e a continuidade do controle ocorreram facilmente, quase sem dificuldades percebidas, emergindo apenas, algumas queixas, principalmente quanto à demora para marcar um exame ou ser atendido no HSP. que devido ao sucateamento dos serviços públicos de saúde, tem recebido grande demanda para os serviços ambulatoriais e de Pronto Socorro.

De acordo com FRENK ${ }^{11}$ a acessibilidade sócio-organizacional facilita o esforço do cliente em obter o cuidado, fenômeno este observado e percebido pelos pacientes no CSE. Esta facilidade propiciou a decisão dos hansenianos, sujeitos dos estudos, quanto a permanecerem em controle no CSE.

Porém, um aspecto que merece reflexão é o princípio da eqüidade vertical referido por MOONEY ${ }^{13}$ que está sendo difícil de ser aplicado na continuidade da assistência ao hanseniano em termos de serviços mais complexos, em decorrência da precariedade de recursos observada há alguns anos e que vem se acentuando na rede de serviços públicos de saúde em São Paulo, aspecto este, também ressaltado por alguns profissionais que atuam no $\mathrm{PCH}$. Como exemplo, cita-se a desativação do serviço fisioterápico prestado num CS de retaguarda que vem comprometendo a assistência requerida pelo hanseniano, principalmente no tocante ao tratamento de lesões incapacitantes que, quando presentes, agem na origem da rejeição e do estigma.

\section{4 - Utilização do CSE}

Os dados sobre a utilização dos serviços prestados no CSE, colhidos nos prontuários dos 
pacientes da amostra evidenciaram que a média de consultas dermatológicas prestadas ao paciente, tanto no primeiro como no segundo ano de controle foi maior que o previsto no cronograma estabelecido no $\mathrm{PCH}$, em função principalmente do atendimento a doentes que apresentaram surtos reacionais e outros problemas de saúde.

A média da consulta na área da Saúde da Mulher foi maior do que o parâmetro estabelecido, em decorrência do controle pré-natal e tratamento de problemas ginecológicos apresentados, respectivamente, por algumas pacientes de hanseníase. Nas consultas de clínica médica, observou-se que o atendimento prestado aos hansenianos, na maioria das vezes era em função do controle da hipertensão e diabetes.

NEMES ${ }^{14}$ analisando a concentração baixíssima da consulta médica eventual no Sub Programa de Controle da Hanseníase da SES no período de 1977 a 1987, comenta que: os doentes de hanseníase não sofrem apenas de hanseníase, apresentando também, sofrimentos ligados a doenças que demandam atendimento eventual; por ser de evolução crônica e pontilhada de episódios agudos freqüentes, que requerem intervenção medica, alguns podendo evoluir rapidamente para incapacidades graves.

A situação colocada por $\mathrm{NEMES}^{14}$, não se reproduziu no CSE, o que pode ser desvelado nos relatos apresentados no item 3 e pela observação e análise da utilização através dos registros em prontuários, realizados pela autora. A dificuldade sentida, tanto por profissionais como pacientes, e o acesso ao sistema de referencia quando necessário, tendo em vista um atendimento mais complexo, já comentado anteriormente.

As médias da consulta de enfermagem e do atendimento na área de ortóptica estão aquém do padrão fixado, principalmente a primeira atividade, em razão de ter sido iniciada a partir de abril de 1989.

A média da pós-consulta foi bem menor do que a encontrada para a consulta medica dermatológica no primeiro e segundo anos de controle. Esta tarefa foi desativada a partir de maio de 1989 tendo como razões, não fragmentar a assistência e permitir ao médico a assunção de seu papel de educador.

Além destas ações, os pacientes utilizaram ainda, os serviços prestados pelo CSE para grupos educativos, curativos, imobilizações, serviço social, atendimento psicológico e para coleta e realização de exames específicos e subsidiários no decorrer do controle.

Estas informações demonstram que no CSE a hanseníase e entendida com uma doença como as outras, promovendo o atendimento do paciente de forma integrada nos vários programas segundo necessidades apresentadas.

\section{Aceitação dos serviços prestados}


Para analisar a aceitação dos serviços prestados pelo CSE, especialmente na área de Dermatologia, apresentam-se a seguir, alguns exemplos de depoimentos que mostram a satisfação dos pacientes com os serviços recebidos. 
"Eles me atendem bem, todos eles são bons. Então, as minhas meninas falam: 'Mas porque vai tão longe' e eu falo: - 'eu vou porque lá eles me tratam bem'. Eu venho feliz e saio contente, eu nunca saí chateada".

"Eles já me propuseram assim: '(nome da paciente), lá perto da sua casa tem um Centro de Saúde" eu falo: - Pelo amor de Deus, vocês estão me expulsando daqui? eu não quero! Eu me sinto tão bem quando eu venho aqui, o pessoal trata como se fosse da família, sabe?".

"Eu comecei a fazer o tratamento aqui e fui muito bem atendida, né? Quer dizer; você já tem o trauma da doença, né?, e chega no local não é bem atendido!!! Então isso faz com que a gente se sinta desestimulado, certo? Eu estou satisfeita com o tratamento e eu tenho uma extrema confiança no Centro de Saúde e nos médicos também, então eu acho que mudar pra outro lugar seria muito desastroso".

"Eu sempre fui atendida bem aqui. Desde que eu comecei a tratar... Acho que eu tive sorte! O atendimento para mim sempre foi bom".

"Agora mesmo quando surgiu esse problema nas minhas costas, eu vim aqui e a Dra. me atendeu. Tomara todos os Centros de Saúde e hospital fossem como aqui".

"Eu gosto mais mesmo é do atendimento, acho que o atendimento é bom. Em vista de outros lugares, aqui é bom".

"Sempre fui bem tratada, eles esclarecem minhas dúvidas, eu não tenho o que me queixar. Inclusive elas me falaram se eu não queria tratar lá, porque era mais perto né? Eu achei melhor continuar aqui. Porque o outro pessoal eu não sei como é, e o pessoal aqui é bem educado".

"Atendem muito bem, a gente aqui não tem porque reclamar, não. No tempo em que eu fiquei ruim eu fui no Centro de Saúde e no Hospital perto da minha casa, né?, e eles mal falou com a gente, sabe? Deu só o endereço pra gente... e lá fomos atendido mal... ".

"Estou satisfeito. É, mas eu acho que eles deviam falar mais um pouco comigo, né? A respeito da doença... ".

"Eles me atendem bem, mas antes eu achava que eles explicavam mais, melhor. Por exemplo, a médica mandou encaminhamento lá pro Centro de Saúde do Jabaquara porque eu tinha que fazer terapia no braço. Então lá no balcão o rapaz falou que estava tudo bem, marcou retorno e mandou eu ir embora. Inclusive teve uma época que tinha um grupo e eu reclamei disso aí. A moça que participava do grupo ela falou: - "Eu vou pôr isso pro diretor', então já começou a melhorar. Eu não gostaria de sair daqui, se me mandarem pro outro Centro de Saúde eu vou 
estranhar. Eles trabalham acho que com gosto, né? porque tem que ter carinho naquilo que a gente faz, né?"

"Eu passo sempre aí no grupo né? o grupo é prá explicar pra gente, pra gente fala sobre o que a gente sente, o pessoal é muito atencioso no grupo. Quando a gente queria falar qualquer coisa que era com o diretor, então eles chamavam o diretor na sala, então a gente falava com eles, eles davam atenção pra gente. Então até, por exemplo, tem uma outra moça e ela falou: - 'Se eu tiver que sair daqui eu paro o tratamento' eu falei: Parar não, né?, porque se de repente a gente é mandada pro outro lugar; mas nunca que é que nem aqui a gente já conhece todo pessoal, eles tratam bem... ".

"Eles não falam quase comigo. Eles me consultam, anotam no papel e falam e falam pra médica o que é. Eu acho que aqui é bom, mas os médicos deveriam falar um pouquinho mais com os pacientes na hora de terminar a consulta".

"Só que antes tinha uma pós-consulta, onde a gente era bem mais esclarecido. E, por exemplo, a hanseníase como é uma doença muito difícil, então eu acho que aqui podia Ter fisioterapia. Então fica a gente indo de um lado pro outro, né? Igual a que fazia lá no Posto do Jabaquara, mas depois foi desativado! E aí a gente ficou sem o acompanhamento. E depois está fazendo muita fala aí é o oculista".

"A gente tem sido bem tratado. Esse é um dos motivos de vir para cá. Porque a gente vai por aí e vê pessoas que só faltam avançar no pescoço da gente! A gente sai mais doente do que quando entrou! Outro dia mesmo eu até tava conversando com o pessoal que se reúne com a gente, as hansenianos, daqui mesmo, o pessoal de consulta. Ate eu tava meio desanimado, aí falei assim, que com essas reviravoltas que tá, se o pessoal daqui for embora, aí é que a gente vai ficar mais abandonado ainda".

Essas falas mostram claramente a satisfação dos pacientes com o atendimento recebido no CSE face ao trato educado e pessoal que recebem é a confiança que depositam na UBS e nos médicos que ali trabalham. Alguns pacientes manifestaram que não gostariam de se transferir para outro local de controle, apesar de residirem longe da UBS. Também ficou evidente em alguns relatos, o espaço dado nas reuniões de grupo, para que os pacientes colocassem suas dúvidas, apreensões e reivindicações, que foram encaminhadas ao diretor do CSE e o "ouvir" com atenção suas colocações. Desta forma, esses espaços podem ser considerados como sendo o "locus" gerador da participação dos hansenianos no processo assistencial desenvolvido na UBS e que merece ser estimulado e ampliado, conforme preconizado pela Reforma Sanitária.

Quanto as restrições apontadas por alguns pacientes, elas se relacionam aos seguintes 
aspectos: desejo de receber mais atenção e orientação sobre a doença, sentir falta das orientações recebidas na pós-consulta, atualmente abolida em UBSs, ausência do oftalmologista no CSE e a desativação do tratamento fisioterápico prestado no CSI do Jabaquara, e a "desatenção" de funcionários da Recepção.

A maioria das restrições percebidas, foi sentida também por profissionais que atuam no $\mathrm{PCH}$, desvelando assim, a convergência de pontos comuns e que ratificam a necessidade de se incluir $O$ usuário e os profissionais na avaliação dos serviços de saúde, com vistas a transformação dos mesmos.

As facetas do fenômeno comentadas pelos pacientes deste estudo e compreendidas na questão da satisfação, são apontadas por FIEDLER ${ }^{10}$ e CASANUEVA et al ${ }^{3}$. Para estes autores, o paciente aceita O serviço quando ele tem confiança na competência técnica e na habilidade humana do profissional responsável pelo seu atendimento. O confronto entre os fatores citados por REIS et al ${ }^{16}$ e os identificados nos depoimentos dos pacientes revela que os mesmos elementos foram valorizados pelos doentes. A comparação dos serviços recebidos no CSE com situações anteriores insatisfatórias vivenciadas em outros serviços de saúde foi evidente e utilizada como ponto de referência para julgar e justificar o "estar satisfeito" e, portanto, a aceitação dos serviços utilizados no CSE.

Para muitos hansenianos, a possibilidade de ser atendido em outra UBS, mesmo que próxima de sua residência, representa uma "expulsão", um desestímulo a continuidade do controle, medo do "abandono" e, principalmente, de uma situação desconhecida onde se desenha a perspectiva de um mau atendimento em razão de experiências pretéritas, ligadas possivelmente a questão do estigma. Considera-se, portanto, correta a postura da equipe do CSE quanto a sua pretensão em respeitar o desejo do paciente em continuar o controle neste serviço mesmo dentro da perspectiva de um atendimento regionalizado dos serviços de saúde.

No entendimento da autora, o paciente de hanseníase é atendido no CSE, como qualquer cidadão deveria ser atendido num serviço público de saúde, isto é, com cortesia, respeito a sua individualidade e privacidade e atenção integral as suas necessidades de saúde, sem demonstração aparente de rejeição, apesar do preconceito estar presente, segundo as falas de alguns profissionais do $\mathrm{PCH}$. A ênfase dada por eles ao componente relacionamento interpessoal - pode estar ligada ao estigma que marca o hanseniano e que promove, ainda, a sua rejeição pela sociedade.

\section{VI - Conclusões}

Do fenômeno estudado extraíram-se as seguintes conclusões:

1. O acesso na sua vertente organizativa, ocorreu sem obstáculos, com exceção, porém, do atendimento em serviços de retaguarda, com prejuízos evidentes para os hansenianos, 
desenhando-se assim lima acessibilidade universal sem eqüidade no seu aspecto vertical para o grupo estudado, o que está diretamente relacionado à política de saúde vigente;

2. a utilização da consulta médica nas áreas de dermatologia e gineco/obstetrícia foi maior do que o padrão estabelecido em decorrência do atendimento a episódios próprios ou não da hanseníase, o que contribuiu para a satisfação desses pacientes;

3. a aceitação dos serviços recebidos foi consensual, com destaque para a satisfação manifestada sobre aspectos que envolvem os componentes técnico e de relacionamento interpessoal, este o mais citado. As experiências pretéritas vivenciadas em outros serviços de saúde - onde prevaleceu o mau atendimento, possivelmente ligado à questão do estigma - desenharam o padrão de referência utilizado pelos pacientes para julgarem a boa qualidade do atendimento prestado no CSE. Essa satisfação geral e a preocupação e receio demonstrados por alguns pacientes com uma possível transferência para outros locais de controle, configuraram um indicador aproximado da boa qualidade da assistência prestada aos hansenianos nessa UBS.

The present Case Study intends to analyze the access, utilization and acceptance of the Dermatology services of a SHC based mainly in the orally reported histories of 27 patients affected by Hansen's disease. The access to SHC - concerning its organization - took place without difficulty, except for the attendance services. However; the utilization level of the services was found to be higher than the established pattern of the care provided whether in actual episodes of the disease or not. The acceptance of the services rendered was consensual and both the technical quality and interpersonal relationship were emphasized.

UN/TERMS: Health administration services; Health services evaluation; Hansen's disease.

Este es un estudio de caso que tiene por finalidad analizar el acceso, la utilización y la aceptación de los servicios de Dermatología de un Centro de Salud Escuela (CSE) y la fuente de datos para análisis consintió, principalmente, de la historia oral narrada por 27 enfermos portadores del mal de Hansen. Según estos pacientes, el acceso al CSE, en lo que refiere al aspecto de organización, ocurrió sin obstáculos, con excepción de los servicios de la retaguardia. La utilización de los servicios fue mayor que el padrón establecido debido a la atención prestada a episodios propios o no de la Hanseniases. La aceptación de los servicios recibidos fue general, con énfasis a los atributos técnicos y de relacionamiento interpersonal.

UNITERMOS: Administración de servicios de salud. Evaluación de servicios de salud. Hanseniasis. 


\section{REFERÊNCIAS BIBLIOGRÁFICAS}

01. ABRASCO. Pelo direito universal a saúde. Rio de Janeiro: Comissão de Política de Saúde, 985. p. 17. (Contribuição da ABRASCO para os debates da VIII Conferência Nacional de Saúde).

02. BRAVO, A. L. Regionalización: organización e funcionamiento coordinado de los servicios de salud en zonas rurales y urbanas. Bol.Of.Sanit.Panam., Washington, v. 77, n. 3, p. 231-243, sept. 1974.

03. CASANUEVA, E. et al; Programa para la captación de una cochorte de estudios perinatales: Il evaluación de la aceptación de un servicio de salud. Bol.or.sanit.Panam., Washington, v. 95, n. 1, p. 44-50, jul. 1983.

04. CASTELLANOS ROBAYO, J. Situaciones de cobertura, niveles de atención y atención primaria. Bol.Of.Sanit.Panam., Washington, v. 82, n. 6, p. 478-491, jun. 1977

05. COMISSÃO NACIONAL DA REFORMA SANITÁRIA. Documento III. Rio de Janeiro: Secretaria Técnica, 1987.

06. CONFERÊNCIA NACIONAL DE SAÚDE, 8., 1986. Brasília, Anais. Brasília: Centro de Documentação do Ministério da Saúde, 1986.

07. CORDERA PASTOR, A. Modelos de atención medica. Salud Públ. México, v. 28, n. 3, p. 230-240, may/june, 1986.

08. DONABEDIAN, A. The quality of care - how can it be assessed? J.Am.Med.Ass., Chicago, v. 260, n. 12, p. 1743-1748, sept. 1988.

09. FERREIRA, J. Vigilância epidemiológica em hanseníase. In: LOMBARDI, C. (Coord.) Hanseníase: epidemiologia e controle. São Paulo: Imprensa Oficial do Estado/ Arquivo do Estado, 1990. p. 33-61.

10. FIEDLER, J.L. A review of the literature on access and utilization of medical care with special emphasis on rural primary care. Soc. Sci. Med., Oxford, v. 15, n. 129-142, 1981.

11. FRENK, J. El concepto y la medic ion de accessibilidad. Salud Públ. Mexico, v. 99, n. 1, p. 438-453, sept./oct. 1985. 
12. MINAYO, M. C. S. O desafio do conhecimento: pesquisa qualitativa em saúde. São Paulo - Rio de Janeiro: Hucitec-Abrasco, 1992. 269 p.

13. MOONEY, G. H. Equity in health care: confronting the confusion. Eff. Health Care, Amsterdam, v. 1, n. 4, p. 179-185, 1983.

14. NEMES, M.I.B. A hanseníase e as práticas sanitárias em São Paulo: 10 anos de subprograma de controle da hanseníase na Secretaria de Estado da Saúde (1977 1987). São Paulo. 194 p. Dissertação (Mestrado) - Faculdade de Medicina, Universidade de São Paulo, 1989.

15. PÉREZ, R., IBARRA, A. M. La evaluación de la satisfacción de la población con los servicios de salud. Rev. Cub. Adm. salud., Habana, v. 11, n. 3, p. 255-262, jul./sept. 1985.

16. REIS, EJ.F.B. et al. Avaliação da qualidade dos serviços de saúde: notas bibliográficas.

Cad. Saúde Públ., Rio de Janeiro, v. 6, n. 1, p. 50-61, jan./mar. 1990.

17. RODRIGUEZ NETO, E. Subsídios para a definição de uma política de atenção à saúde para um governo de transição democrática. Saúde Deb., Rio de Janeiro, n. 17, p. 1217, jul. 1985.

18. TRIVINOS, A. N. S. Introdução a pesquisa em ciências sociais. São Paulo: Atlas, 1987. 157 p.

19. YUNES, J. Participação social em saúde. In: CONFERÊNCIA NACIONAL DE SAÚDE, 8., 1986, Brasília. Anais. Brasília: Centro de Documentação do Ministério da Saúde, 1986. p.133-140. 